\title{
PENURUNAN KANDUNGAN BOD, COD, TSS, WARNA DAN PENGENDALIAN PH LIMBAH CAIR BATIK MENGGUNAKAN PROSES ELEKTROKOAGULASI TAHUN 2015
}

Novika Hildayanti, Sudjarwo, Fitri Rokhmalia

\section{ABSTRACT}

Home industry batik is among the largest producers of liquid waste originating from the dyeing process. Those home industries discharge liquid waste to the surrounding water determine the capability of electrocoagulation to reduce the contents of BOD, COD, TSS, color and pH of liquid water from batik home industry. cathode.

Electrocoagulation was used in the study with a stainless steel anode and an aluminium

Result showed a decrease in BOD content from $855,85 \mathrm{mg} / \mathrm{l}$ at minute 30 to $54,42 \mathrm{mg} / \mathrm{l}$ at minute 180. There was decrease in COD content from $1685,9 \mathrm{mg} / \mathrm{l}$ at minute 30 to $98,30 \mathrm{mg} / \mathrm{l}$ at minute 180. There was decrease in TSS content from $720 \mathrm{mg} / \mathrm{l}$ at minute 30 to $50 \mathrm{mg} / \mathrm{l}$ at minute 180. There was decrease in color content from $242 \mathrm{TCU}$ at minute 30 to 10,66 TCU at minute 180. An increase in $\mathrm{pH}$ of 6,9 occurred from minute 30 and remained stable for next minutes.

They goverment is recommended to use electrocoagulation equipment since it fairly effective to reduce the contents of BOD, COD, TSS, color and $\mathrm{pH}$ in order for the liquid batik waste to meet the quality standards of Eat Java Governor Regulation No. 72 of 2013. Electrocoagulation equipment is quite easy to make and it can be designed according to local people conditions.

Keyword : liquid batik waste, electrocoagulation, BOD, COD, TSS, color, pH

\section{PENDAHULUAN}

Desa Tanjung Bumi merupakan salah satu daerah pengrajin batik di Kecamatan Tanjung Bumi Kabupaten Bangkalan. Home industry batik merupakan salah satu penghasil limbah cair yang berasal dari proses pewarnaan, selain kandungan zat warnanya tinggi. Dari hasil uji lab, didapat data bahwa beban pencemar BOD sebesar $862,91 \mathrm{mg} / \mathrm{l}$. Beban pencemar COD sebesar $1733,04 \mathrm{mg} / \mathrm{l}$, beban pencemar TSS sebesar $740 \mathrm{mg} / \mathrm{l}$, beban pencemar warna sebesar $242 \mathrm{TCU}$, dan $\mathrm{pH}$ sebesar 4. Sampai saat ini, limbah tersebut langsung dibuang ke badan air dan tanah kosong di sekitar home industry. Jika hal ini dilakukan secara terus-menerus, maka lambat laun akan mengakibatkan pencemaran badan air.

\section{Tujuan}

Mengetahui kemampuan proses elektrokoagulasi untukmenurunkan kandungan BOD, COD, TSS, warna dan $\mathrm{pH}$ limbah cair home industry batik.

\section{METODE PENELITIAN}

\section{Jenis Penelitian}

Penelitian yang dilakukan adalah penelitian eksperimen dan jenisnya adalah eksperimen semu (Quasi experiment), dengan rancangan Pre-Post TestDesign.

\section{Sampel Penelitian}

Sampel yang digunakan adalah limbah cair batik home industry yang terbesar di Desa Tanjung Bumi Kecamatan Tanjungbumi Kabupaten Bangkalan.

\section{Tahap Penelitian}

Bahan dan Cara Pembuatan Alat

a. Bahan :
1) Adaptor
2) Elektroda
3) $\mathrm{pH}$ meter
4) Kabel penghubung
5) Jepit buaya
6) Tong plastik biru $200 \mathrm{~L}$
7) Pengaduk
8) Stopwatch

b. Pembuatan Alat Elektrokoagulasi

1) Bak elektrokoagulasi

Bak elektrokoagulasi terbuat dari tong plastik biru dengan ukuran 200 L. Penelitian dilakukan menggunakan metode batch.

2) Elektroda

Ukuran elektroda masing-masing berukuran panjang $=30 \mathrm{~cm}$ dan lebar $=15 \mathrm{~cm}$. Reaktor terpasang 6 pasang elektroda. 
Gambar 1 Reaktor Proses Elektrokoagulasi

Plat Al dan Stainless steel

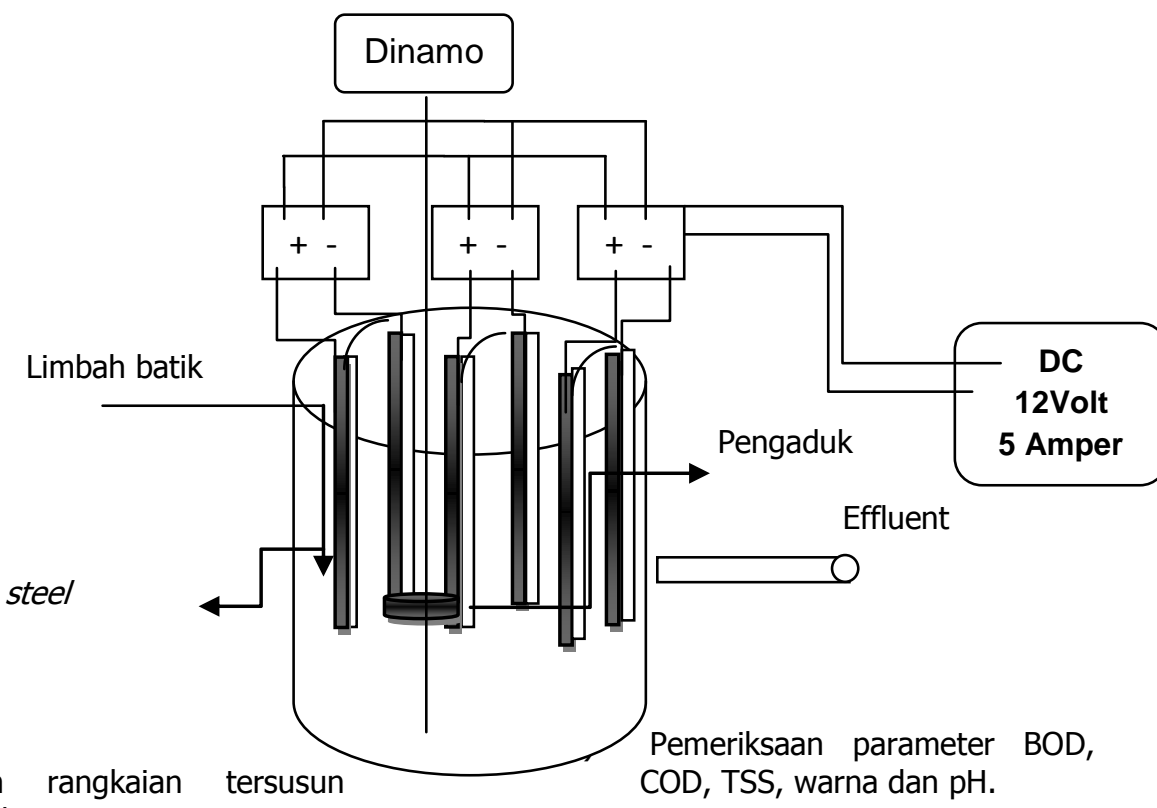

1) Pastikan rangkaian tersusun COD, TSS, warna dan $\mathrm{pH}$ dengan benar

2) Masukkan limbah kedalam bak elektrokoagulasi

3) Nyalakan listrik dengan tegangan 12 Volt dan kuat arus 5 Ampere selama 30 menit, 60 menit, 90 menit, 120 menit, 150 menit dan 180 menit.

4) Pengambilan sampel dilakukan tiap 30 menit. Pengambilan sampel melalui aliran outlet mengunakan volume dan waktu yang diinginkan.

\section{Analisis Data}

Analisa dilakukan secara analitik untuk mengetahui perbandingan sesbelum dan sesudah dilakukan proses elektrokoagulasi dan tingkat efisiensi penurunan kandungan $\mathrm{BOD}, \mathrm{COD}$, TSS, warna dan pengendalian pada limbah cair batik.

HASIL PENELITIAN DAN PEMBAHASAN

\section{BOD}

Tabel 1

Analisa Penurunan Kandungan BOD

\begin{tabular}{|c|c|r|r|r|r|}
\hline No & Voltase (Volt) & $\begin{array}{c}\text { Jarak Elektroda } \\
(\mathrm{cm})\end{array}$ & $\begin{array}{c}\text { Waktu } \\
\text { (Menit) }\end{array}$ & $\begin{array}{c}\text { Hasil BOD } \\
(\mathrm{mg} / \mathrm{l})\end{array}$ & Efisiensi (\%) \\
\hline & 110 & 1,5 & 0 & 862,91 & 0,00 \\
\hline & 110 & 1,5 & 30 & 855,85 & 0,81 \\
\hline & 110 & 1,5 & 60 & 748,54 & 13,20 \\
\hline & 110 & 1,5 & 90 & 500,54 & 41,84 \\
\hline & 110 & 1,5 & 120 & 376,42 & 56,37 \\
\hline & 110 & 1,5 & 150 & 213,92 & 75,55 \\
\hline & 110 & 1,5 & 180 & 52,42 & 93,92 \\
\hline
\end{tabular}

Sumber : Data Primer

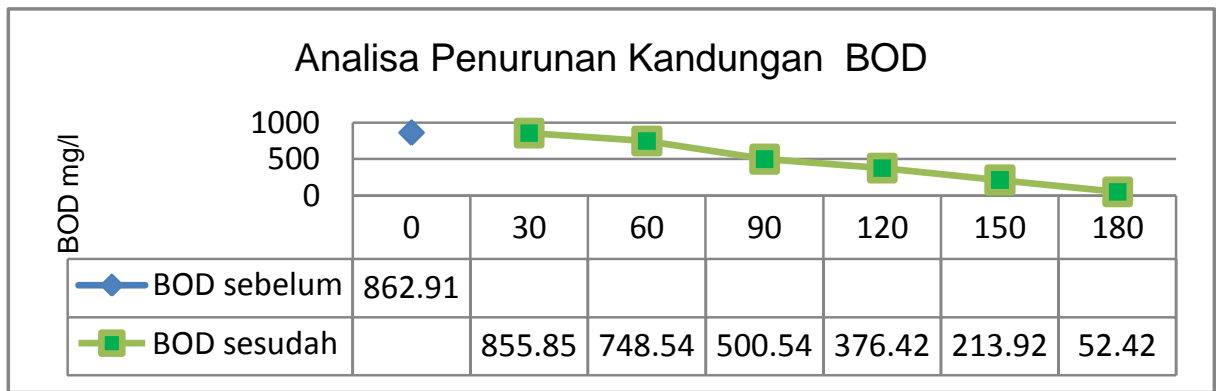

Grafik 1 Analisa Penurunan Kandungan BOD 
Berdasarkan Tabel dan Gambar diatas dapat dilihat bahwa hasil awal pemeriksaan BOD sebelum dilakukan proses elektrokoagulasi sebesar $862,91 \mathrm{mg} / \mathrm{l}$. Dilakukan pemeriksaan mulai menit ke 30 kandungan BOD masih tinggi yaitu 855,85 $\mathrm{mg} / \mathrm{l}$. Sedangkan pada menit ke 180 kandungan BOD turun menjadi 52,42 $\mathrm{mg} / \mathrm{l}$, sehingga sudah memenuhi standar baku mutu air limbah dari Peraturan Gubernur Jawa Timur No. 72
Tahun 2013.

Dan juga disebabkan semakin lama waktu kontak yang diberikan berpengaruh terhadap penurunan BOD pada limbah batik. Dimana koagulan yang terbentuk dalam proses elektrokoagulasi dikarenakan adanya proses oksidasi dan reduksi yang dapat membantu menurunkan kandungan BOD dalam air limbah batik.

2. COD

Tabel 2

Analisa Penurunan Kandungan COD

\begin{tabular}{|r|r|r|r|r|r|}
\hline \multicolumn{1}{|r|}{ No } & \multicolumn{1}{|c|}{$\begin{array}{c}\text { Voltase } \\
\text { (Volt) }\end{array}$} & $\begin{array}{c}\text { Jarak } \\
\text { Elektroda } \\
(\mathrm{cm})\end{array}$ & $\begin{array}{c}\text { Waktu } \\
\text { (Menit) }\end{array}$ & Hasil COD (mg/l) & Efisiensi (\%) \\
\hline 1 & 110 & 1,5 & 0 & 1733,04 & 0,00 \\
\hline 2 & 110 & 1,5 & 30 & 1685,9 & 2,72 \\
\hline 3 & 110 & 1,5 & 60 & 1240,36 & 28,42 \\
\hline 4 & 110 & 1,5 & 90 & 1056,22 & 39,05 \\
\hline 5 & 110 & 1,5 & 120 & 652,69 & 62,33 \\
\hline 6 & 110 & 1,5 & 150 & 371 & 78,59 \\
\hline 7 & 110 & 1,5 & 180 & 98,30 & 94,32 \\
\hline
\end{tabular}

Sumber : Data Primer

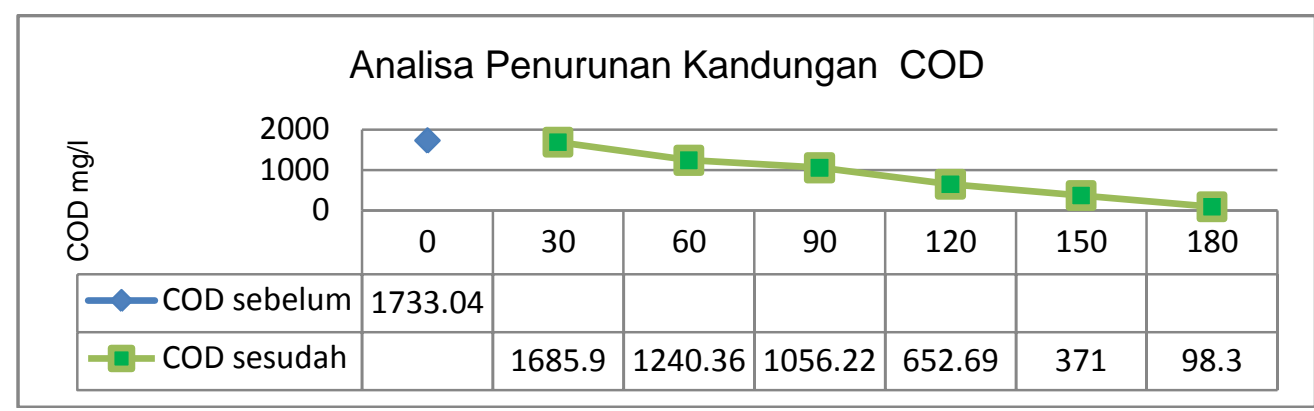

Grafik2 Analisa Penurunan Kandungan COD

Berdasarkan Tabel 2 dan Gambar 2 dapat dilihat bahwa hasil awal pemeriksaan COD sebelum dilakukan proses elektrokoagulasi sebesar 1733,04mg/l. Dilakukan pemeriksaan mulai menit ke 30 kandungan COD masih tinggi yaitu $1685,9 \mathrm{mg} / \mathrm{l}$. Sedangkan pada menit ke 180 kandungan COD turun menjadi $98,30 \mathrm{mg} / \mathrm{l}$, sehingga sudah memenuhi standar baku mutu air limbah dari Peraturan Gubernur Jawa Timur No. 72 Tahun 2013.Penurunan konsentrasi
COD dalam elektrokoagulasi ini dikarenakan proses oksidasi dan reduksi didalam reaktor elektrokoagulasi tersebut. Pada elektrodaelektroda terbentuk gas, seperti oksigen dan hidrogen ini akan mempengaruhi pereduksian COD. Penurunan COD di karenakan flok yang terbentuk oleh ion senyawa organik berikatan dengan ion koagulan yang bersifat positif.

\section{TSS}


Tabel 3

Analisa Penurunan Kandungan TSS

\begin{tabular}{|r|r|r|r|r|r|}
\hline \multicolumn{1}{|r|}{ No } & \multicolumn{1}{|c|}{$\begin{array}{c}\text { Voltase } \\
\text { (Volt) }\end{array}$} & $\begin{array}{c}\text { Jarak } \\
\text { Elektroda } \\
(\mathrm{cm})\end{array}$ & $\begin{array}{c}\text { Waktu } \\
\text { (Menit) }\end{array}$ & \multicolumn{1}{c|}{$\begin{array}{c}\text { Hasil TSS } \\
(\mathrm{mg} / \mathrm{l})\end{array}$} & Efisiensi (\%) \\
\hline 1 & 110 & 1,5 & 0 & 740 & 0,00 \\
\hline 2 & 110 & 1,5 & 30 & 720 & 2,70 \\
\hline 3 & 110 & 1,5 & 60 & 536,66 & 27,47 \\
\hline 4 & 110 & 1,5 & 90 & 416,66 & 43,69 \\
\hline 5 & 110 & 1,5 & 120 & 276,66 & 62,61 \\
\hline 6 & 110 & 1,5 & 150 & 153,33 & 79,27 \\
\hline 7 & 110 & 1,5 & 180 & 50 & 93,24 \\
\hline
\end{tabular}

Sumber : Data Primer

\begin{tabular}{|c|c|c|c|c|c|c|c|}
\hline \multicolumn{8}{|c|}{ Analisa Penurunan Kandungan TSS } \\
\hline \multirow{2}{*}{$\begin{array}{r}1000 \\
500 \\
0\end{array}$} & \multicolumn{7}{|c|}{1} \\
\hline & 0 & 30 & 60 & 90 & 120 & 150 & 180 \\
\hline- TSS sebelum & 740 & & & & & & \\
\hline - - TSSsesudah & & 720 & 536.66 & 416.66 & 276.66 & 153.33 & 50 \\
\hline
\end{tabular}

Grafik3 Analisa Penurunan Kandungan TSS

Berdasarkan Tabel 3 dan Gambar 3 dapat dilihat bahwa hasil awal pemeriksaan TSS sebelum dilakukan proses elektrokoagulasi sebesar $740 \mathrm{mg} / \mathrm{l}$. Dilakukan pemeriksaan mulai menit ke 30 kandungan TSS masih tinggi yaitu 720 $\mathrm{mg} / \mathrm{l}$. Sedangkan pada menit ke 180 kandungan TSS turun menjadi $50 \mathrm{mg} / \mathrm{l}$, sehingga sudah memenuhi standar baku mutu air limbah dari Peraturan Gubernur Jawa Timur No. 72 Tahun 2013.

Penelitian yang telah dilakukan bahwa semakin lama waktu proses elektrokoagulasi, maka semakin besar penurunan TSS. Hal ini disebabkan semakin lama waktu proses dalam reaktor, kontak antara air limbah dengan elektroda berlangsung lebih lama penguraian senyawa - senyawa organik atau solid yang terdapat dalam air limbah batik berlangsung dengan baik dan kotoran air limbah akan terikat menjadi flok - flok sehingga menurunkan jumlah total sollid.

\section{Warna}

Tabel 4

Analisa Penurunan Kandungan Warna

\begin{tabular}{|r|r|r|r|r|r|}
\hline \multicolumn{1}{|r|}{ No } & \multicolumn{1}{|c|}{$\begin{array}{c}\text { Voltase } \\
\text { (Volt) }\end{array}$} & $\begin{array}{c}\text { Jarak } \\
\text { Elektroda } \\
(\mathrm{cm})\end{array}$ & $\begin{array}{c}\text { Waktu } \\
\text { (Menit) }\end{array}$ & \multicolumn{1}{c|}{$\begin{array}{c}\text { Hasil Warna } \\
\text { (TCU) }\end{array}$} & Efisiensi (\%) \\
\hline 1 & 110 & 1,5 & 0 & 242 & 0,00 \\
\hline 2 & 110 & 1,5 & 30 & 242 & 0,00 \\
\hline 3 & 110 & 1,5 & 60 & 176,33 & 27,13 \\
\hline 4 & 110 & 1,5 & 90 & 150,33 & 38,01 \\
\hline 5 & 110 & 1,5 & 120 & 96 & 60,33 \\
\hline 6 & 110 & 1,5 & 150 & 75,66 & 68,73 \\
\hline 7 & 110 & 1,5 & 180 & 10,66 & 95,55 \\
\hline
\end{tabular}

Sumber : Data Primer 


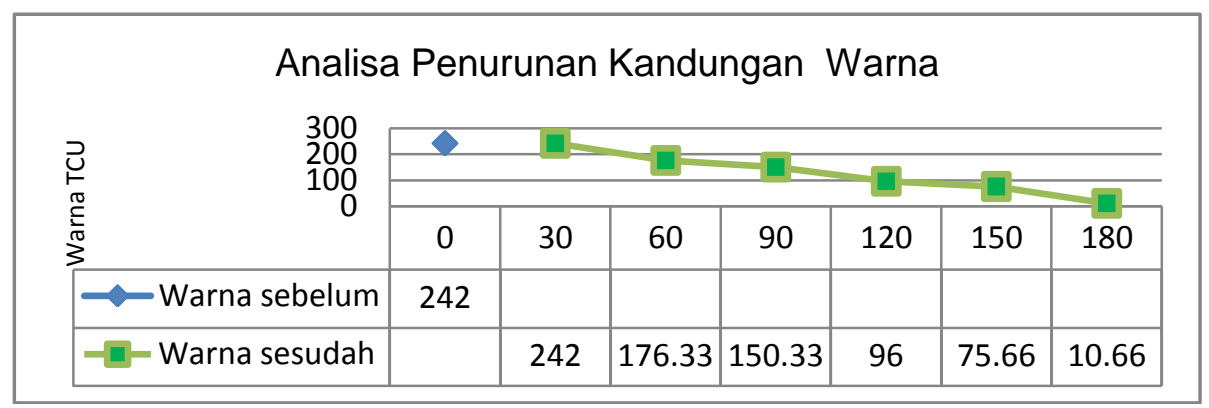

Grafik4 Analisa Penurunan Kandungan Warna

Berdasarkan Tabel 4 dan Gambar 4 dapat dilihat bahwa hasil awal pemeriksaan warna sebelum dilakukan proses elektrokoagulasi sebesar 242 TCU. Dilakukan pemeriksaan mulai menit ke 30 kandungan warna masih tinggi yaitu 242 TCU. Sedangkan pada menit ke 180 kandungan warna turun menjadi 10,66 TCU.

Hal ini disebabkan oleh proses adsorbsi, dimana substansi molekul meninggalkan larutan limbah dan bergabung pada permukaan zat padat (koagulan) dari proses elektrokoagulasi. Proses adsorbsi disini berfungsi untuk menyisihkan senyawa organik terlarut. Pewarna sintetik yang digunakan yaitu indigosol, napthol, indanthreen.

5. $\mathrm{pH}$

Tabel 5

Analisa Pengendalian Kandungan pH

\begin{tabular}{|r|r|r|r|r|r|}
\hline \multicolumn{1}{|r|}{ No } & \multicolumn{1}{|c|}{$\begin{array}{c}\text { Voltase } \\
\text { (Volt) }\end{array}$} & \multicolumn{1}{c|}{$\begin{array}{c}\text { Jarak } \\
\text { Elektroda } \\
(\mathrm{cm})\end{array}$} & $\begin{array}{c}\text { Waktu } \\
\text { (Menit) }\end{array}$ & Hasil pH & Efisiensi (\%) \\
\hline 1 & 110 & 1,5 & 0 & 4 & 0,00 \\
\hline 2 & 110 & 1,5 & 30 & 6,9 & 72,50 \\
\hline 3 & 110 & 1,5 & 60 & 6,9 & 72,50 \\
\hline 4 & 110 & 1,5 & 90 & 6,9 & 72,50 \\
\hline 5 & 110 & 1,5 & 120 & 6,9 & 72,50 \\
\hline 6 & 110 & 1,5 & 150 & 6,9 & 72,50 \\
\hline 7 & 110 & 1,5 & 180 & 6,9 & 72,50 \\
\hline
\end{tabular}

Sumber : Data Primer

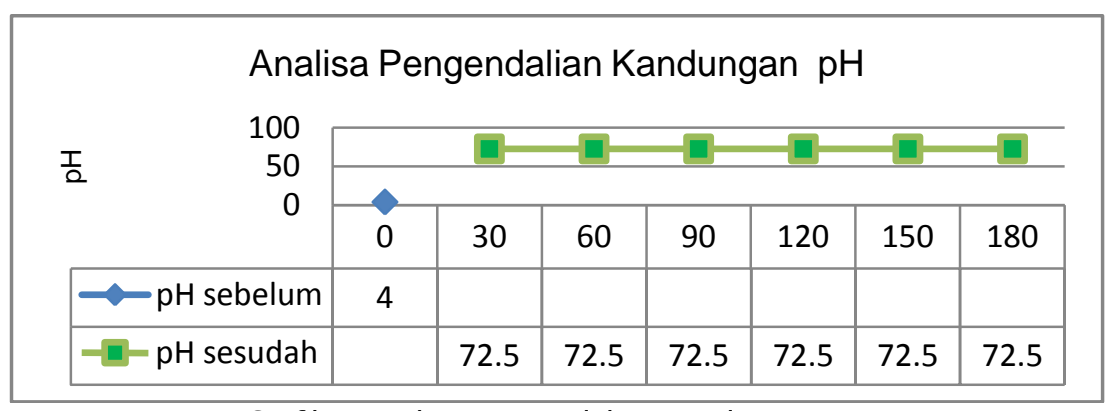

Grafik 5 Analisa Pengendalian Kandungan pH 
Berdasarkan Tabel 5 dan Gambar 5 dapat dilihat bahwa hasil awal pemeriksaan $\mathrm{pH}$ sebelum dilakukan proses elektrokoagulasi sebesar 4. Dilakukan pemeriksaan mulai menit ke 30 kandungan $\mathrm{pH}$ sudah memenuhi standar baku mutu air limbah dari Peraturan Gubernur Jawa Timur No. 72 Tahun 2013 yaitu sebesar 6,9.

Keasaman larutan mempunyai pengaruh terhadap kemudahan pembebasan Hidrogen dan Oksigen, dengan berkurangnya pembebasan Hidrogen maupun pembebasan Oksigen menjadi lebih mudah.pH asam akan cepat membantu proses elektrokoagulasi karena logam yang terdapat dalam limbah akan mengendap.

KESIMPULAN Kandungan BOD sebelum dilakukan proses elektrokoagulasi sebesar 852,91mg/l dan efisiensi penurunan kandungan BOD untuk pemenuhan standar baku mutu Peraturan Gubernur Jawa Timur No. 72 Tahun 2013 pada menit ke 180 adalah 93,92 \% sebesar 52,42 mg/l.

1. Kandungan COD sebelum dilakukan proses elektrokoagulasi sebesar $1733,04 \mathrm{mg} / \mathrm{l}$ dan efisiensi penurunan kandungan COD untuk pemenuhan standar baku mutu Peraturan Gubernur Jawa Timur No. 72 Tahun 2013 pada menit ke 180 adalah $94,32 \%$ sebesar 98,30 $\mathrm{mg} / \mathrm{l}$.

2. Kandungan TSS sebelum dilakukan proses elektrokoagulasi sebesar 740 $\mathrm{mg} / \mathrm{l}$ dan efisiensi penurunan kandungan TSS untuk pemenuhan standar baku mutu Peraturan Gubernur Jawa Timur No. 72 Tahun 2013 pada menit ke 180 adalah $93,24 \%$ sebesar $50 \mathrm{mg} / \mathrm{l}$.

3. Kandungan warna sebelum dilakukan proses elektrokoagulasi sebesar 242 TCU dan efisiensi penurunan kandungan warna adalah 95,55 \% sebesar 10,66 TCU.

4. Kandungan $\mathrm{pH}$ sebelum dilakukan proses elektrokoagulasi sebesar danefisiensi pengendalian kandungan $\mathrm{pH}$ untuk pemenuhan standar baku mutu Peraturan Gubernur Jawa Timur No. 72 Tahun 2013 pada menit ke 30 adalah $72,50 \%$ yaitu sebesar 6,9 .

\section{SARAN}

1. Bagi Pemilik Home Industry Batik Air limbah batik sebelum dibuang sebaiknya diolah menggunakan alat
elektrokoagulasi.Alat elektrokoagulasi pada penelitianinimenggunakan tegangan 12 Volt, kuat arus 5 Ampere dan 6 pasang elektroda.karena alat elektrokoagulasi cukup efektif untuk menurunkan kandungan BOD, COD, TSS, warna, $\mathrm{pH}$ sehingga air limbah batik memenuhi standar baku mutu Peraturan Gubernur Jawa Timur No. 72 Tahun 2013.

2. Bagi Peneliti Lain

Bagi peneliti laindapat melakukan penelitian lanjutan dengan penambahan elektroda, maka perlu diamati pengaruhnya.

\section{DAFTAR PUSTAKA}

Ardhani, A.F dan Ismawati, D. 2007. Penanganan Limbah Cair Rumah Pemotongan Hewan Dengan Metode Elektrokoagulasi.Yogyakarta,Gajah Mada University Press

Asmadi dan Suharno, 2012.Dasar-Dasar Pengolahan Limbah Cair. Yogyakarta,Gosyen Publising.

Juminingsih, 2008. Penurunan Kekeruhan Dengan Metode Eelektrokoagulasi.

Menggunakan Aluminium (Al), Besi (Fe), dan Seng (Zn) Sebagai Anoda Dan Karbon (C) Seabagai Katoda. Surabaya, ITS Press.

Mukimin, A. 2006. Pengolahan Limbah Industri Berbasis Logam Dengan Teknologi Eelektrokoagulasi flotasi.Semarang, UPT Undip Press.

Masita, D.2013.Studi Penurunan Konsentrasi Khromium Dan Tembaga Dalam Pengolahan Llimbah Cair Elektroplating Artificial Dengan Metode Eelektrokoagulasi. Semarang, UPT Undip Press

Peraturan Gubernur Jawa Timur No. 72 Tahun 2013 Tentang Baku Mutu Air Limbah Bagi Industri Dan/Atau Kegiatan Usaha Lainnya.

Peraturan Pemerintah Republik Indonesia No. 82 Tahun 2001 Tentang Pengelolaan Kualitas Air Dan Pengendalian Pencemaran Air.

Purwanto, D.S, 2006. Pengolahan Limbah Cair. Surabaya, Duatujuh.

Purwanto, D.S, 2012. Pengelolaan Limbah Cair. Surabaya, Duatujuh.

Riyanto, Ph. D, 2012. Elektrokimia Dan Aplikasinya. Yogyakarta, Graha Ilmu.

Suharto, 2011.Limbah Kimia dalam Pencemaran Air. Yogyakarta, ANDI.

Trapsilasiwi, K.R. Aplikasi Elektrokimia Mengunakan Pasangan Elektroda Aluminium (Al) Untuk Pengolahan Air Dengan Sistem Kontinyu. Surabaya, ITS Press. 